\title{
Reconfiguration of Six Teaching Links in the Intelligent Teaching Model
}

\author{
Jing Huang Yong Zhang* \\ Yancheng Teachers University, Jiangsu 224002, China \\ * E-mail of the corresponding author: zyyctc@126.com
}

The research is part of the achievements of the research project of higher education reform in Jiangsu Province.No.2019JSJG257(Sponsoring information)

\section{Abstract}

The six teaching links include teaching, learning, practicing, testing, evaluating, and managing. Over time, the traditional classroom has some problems in implementing six teaching links, such as teacher-centered, unchanging teaching content, and inertia of student learning. With the support of the series of functions of intelligent teaching tools, the six teaching links are integrated into the pre-class, in-class, and post-class. And the six links are reconstructed in the three stages of pre-class preview, in-class teaching, and post-class consolidation, thus students' learning ability can be comprehensively improved.

Keywords: Six teaching links; Intelligent teaching; Teaching reconfiguration

DOI: $10.7176 / \mathrm{JEP} / 12-29-01$

Publication date:October $31^{\text {st }} 2021$

\section{Six teaching links}

Over time, most front-line teachers have formed six major teaching links in the process of teaching practice, namely: teaching, learning, practicing, examining, evaluating, and managing. Teachers give lectures in class, students listen in class, complete the exercises assigned by teachers, participate in the examinations arranged by teachers, teachers evaluate students' academic achievements, and manage the teaching process and students' achievements.

In traditional teaching, teachers divide a semester's teaching content into several chapters, make lesson plans and teaching objectives, and then use the six parts of teaching, learning, practicing, examining, evaluating, and managing to promote teaching. Students who do not reach the standard are given timely correction until they achieve it. After that, teachers will move on to the next chapter of the six links. Through the cycle, students can achieve the learning objectives of a semester.

It is undeniable that the implementation of the six parts of traditional teaching can guarantee the transmission and acceptance of knowledge and promote a virtuous cycle of teaching and learning activities. However, its problems cannot be ignored, mainly in the following ways:

First, teacher centered. The teacher is the dominant person in teaching activities, and students mainly follow the teacher's thinking into all aspects of teaching. Second, the teaching content is unchanged. Complete the prescribed tasks for each session as designed in the lesson plan, regardless of the students' learning abilities. Third, it develops students' inertia in learning. Students are always in a passive acceptance position in all aspects of teaching and learning and inevitably form learning inertia, satisfied with mastering knowledge instead of thinking about it and judging it.

As a result, the traditional implementation of six teaching links is not as effective as it could be. "The effectiveness of teachers' instruction is actually far from expectations and is still largely focused on developing students' memory and comprehension skills, with little opportunity to reach the level of developing students' higher-level thinking skills." [1] In the 1950s, American psychologist Carl Ransom Rogers introduced the concept of "student-centeredness". In Freedom to Learn, he proposed that "the goal of education should be to promote change and learning, to develop people who can adapt to change and know how to learn". ${ }^{[2]}$ Once the concept of "student-centered" was put forward, it has attracted widespread attention and many scholars at home and abroad have given full affirmation to the value of this concept. For example, Tian Xin argues that "colleges and universities should change the traditional 'teaching'-centered education concept to a 'student-centered' talent cultivation concept." ${ }^{[3]}$ In order to achieve true " student-centered ", it is necessary to reconstruct the traditional six teaching links, putting students at the center of the classroom, making the teacher the organizer and guide of teaching, and adopting a problem-oriented approach to promote students' active thinking and learning. The reconfiguration of six teaching links relies on the use of intelligent teaching tools.

\section{Use of intelligent teaching tools}

Under the new normal of epidemic prevention and control, intelligent teaching is becoming more and more prosperous in order to achieve "stopping school without stopping classes". The so-called intelligent teaching is the use of cloud computing, big data, mobile Internet, and other modern scientific and technological means to 
implement intelligent teaching. Intelligent pedagogy is a balance of the complex relationship between teaching technology, subject knowledge and teaching methods under educational information technology." [4] The development of intelligent teaching must rely on specific intelligent teaching tools. Although there are various smart teaching tools available, in general, smart teaching tools tend to have the following functions:

First, push function. Teachers can send various learning resources to students, such as pre-study materials, assignments, test papers, videos, audios, pictures, PPTs, etc. Second, the teacher-student interaction function. Teachers can enhance teacher-student interaction by random selection, real-time comments, classroom red envelopes, raising hands, rush-answer, etc. Third, the assignment test function. Teachers can conduct timelimited accompanying tests, as well as post-class paper exams, and set the submission deadline. Fourth, the instant feedback function. Students can give feedback on what they don't understand at any time and get instant feedback on the answers after submitting their answers. Fifth, the data report function. The system automatically generates detailed learning statistics reports for each student, and teachers can analyze each student's specific learning performance according to the reports.

There are many benefits of using intelligent teaching tools, such as:

First, richer learning resources. Teachers and students do not need to be limited to the content of the textbook, and teachers can upload various teaching resources related to the content at any time. Second, more diverse learning methods. Students can learn online anytime and anywhere, and can also meet the diverse needs of quizzing, voting, discussion, homework, question and answer, feedback on grades and answers, etc. So, students can truly become the main body of teaching. Third, the learning effect is more obvious. Students' learning in each session is recorded and analyzed in the background, which makes it easy for teachers to understand the status of learning and make timely adjustments.

Overall, teachers and students can reconstruct the six links of teaching under the intelligent teaching mode only by mastering the methods of intelligent teaching tools.

\section{Reconfiguration of six teaching links in an intelligent teaching model}

Unlike the sequential implementation of the six links in traditional teaching, the basic concept of reconstructing the six-teaching links in the smart teaching mode is to rearrange the knowledge points and integrate teaching, learning, practice, examination, evaluation, and management into each stage before, during and after class, to achieve a comprehensive reconstruction of traditional teaching in terms of pre-study before class, in-class teaching, and consolidation after class.

(1) Reconstructing the six components of pre-course pre-reading

In traditional teaching, students are usually given pre-reading tasks before class, but the teacher often does not check the effectiveness of the pre-reading. By using intelligent teaching tools, six teaching links before class can be built.

Before the lesson, teachers use intelligent teaching tools to upload learning resources and independent tests to guide students to "learn" independently according to what they are "taught" in the learning resources. Afterward, students are required to complete relevant discussions, questionnaires, tests, short essays, and other "practice" and "test" tasks. Teachers use back-end data to "manage" students, keep track of their learning, and remind students who have not yet viewed learning resources or completed assignments. Teachers also need to " evaluate" on students' assignments submitted to the intelligent platform, commenting, and scoring them. The implementation of six pre-class teaching links in intelligent teaching turns the original inefficient pre-class prestudy into a guided and efficient pre-class pre-study, widens the teaching space, exercises the students' independent learning ability, and improves the overall teaching effect.

(2) Restructuring in-class six teaching links

In traditional classrooms, the focus is on "teaching," and students' motivation is neglected. By using intelligent teaching tools, students' learning potential can be further explored by forming interactive, seminar-style, and generative teaching while adhering to the six elements of teaching.

Ten minutes before class, teachers use intelligent teaching tools to initiate check-in and instantly count attendance. This " management" is helpful to urge students to be fully prepared and to be in class on time, thus ensuring the seriousness and smooth running of classroom teaching.

In the process of teaching, the teacher's "teaching" mainly plays the role of "pointing out and guiding" so that students' understanding can be improved. Students "learn" with problems, and the process of learning is the process of thinking and problem-solving. Based on "learning," we use the functions of intelligent teaching tools, such as discussion, voting, and quiz, to guide students to participate and express their own views fully. Teachers need to " evaluate" students' independent research in a timely manner, usually with motivational evaluation, using a combination of verbal comments and extra points in the tool or using features such as classroom bonuses.

After completing a task in class, teachers use the testing function of the Smart Platform to issue accompanying test questions, with questions of multiple-choice, True or False, etc., focusing on testing students' understanding of classroom knowledge. Teachers can use a retrospective approach to review tests on previously 
asked questions to facilitate a quick grasp of students' mastery of a particular knowledge point. Before the end of a class, teachers can leave five minutes to assess the knowledge of the class for improvement, through the "test" results, to fully grasp the students' learning situation in this class, and provide the basis for the assignment after the class.

(3) Reconstructing the six post-class consolidation links

In traditional teaching, the six elements of "teaching, learning, practicing, examining, evaluating, and managing" also exist after class, but their implementation is not satisfactory. Although teachers will assign appropriate homework for students to practice after class or even issue test papers for students to assess themselves, it is difficult to achieve the expected purpose because of the lack of effective supervision. The mode of operation in which students submit homework assignments, and after the teacher corrects and gives feedback, he/she makes appropriate explanations and comments, so that students can learn again, which also makes the "teaching" and "learning" at the end of the lesson ineffective due to its limitation of the long process and slow feedback. Smart teaching mode can realize the reconstruction of six teaching links after class.

First, "teaching" and "learning" are reconstructed. According to the background statistics of the intelligent teaching platform, teachers sort out the learning situation of each student and provide individual tutoring for students with less than satisfactory performance so as to implement personalized "teaching" and "learning." At the same time, we push micro-lessons, research papers, or supplemental teaching videos for students to learn again in order to raise awareness of important and difficult teaching points, as well as common problems that students generally have.

Second, "practice" and "test" are reconstructed. Teachers use intelligent teaching tools to upload after-class assignments and divide task groups to discuss and complete more reflective topics. Teachers also can upload test questions with deadlines and time limits for completion. A combination of system correction, student peer review, and teacher correction is used according to the demand. After the correction, the system automatically displays the reference answers of the homework and the students' grades.

Third, "management" and "evaluation" are reconstructed. Use the platform to comprehensively grasp the student's student dynamics and make an objective assessment of the teaching operation and teaching effect. Regular feedback on students' learning reports and detailed data, including check-in, completion of video resources, non-video resources, polling questionnaires, tests, assignments, etc., allows students to have a clear understanding of their learning status over time.

\section{Conclusion}

In recent years, many countries have made smart education a major strategy for education development. A while ago, at the "2021 Global Smart Education Conference", experts in education and technology from China, the United States, Russia, the United Kingdom, Germany, and other countries discussed the impact of smart technology on the future of education, smart technology for education equity and balance, global smart education strategies and sustainable development, and the new normal of "Internet + education" during the COVID-19 epidemic. The study of the intelligent teaching model has become a hot spot and a focus of pedagogical research in the new situation. It is a new challenge for educators to push forward and reconstruct traditional teaching methods so that they can take on a new life in the context of intelligent teaching. This paper explores how to integrate six teaching links before, during, and after class to reconfigure teaching methods while familiarizing with relevant smart teaching tools. The reconfiguration of six teaching links under the intelligent teaching model helps students to stimulate their interest in learning, enhance their learning autonomy, improve their knowledge mastery and develop their creative thinking skills in the intelligent learning space created by teachers, thus "providing a real learning process for learners and achieving the overall development of their abilities." [5]

\section{References}

[1]Zhu Zhiting, Lei Yunhe. (2006) Flipped classroom 2.0: Towards creation-driven intelligent learning [J]. Research in Electro-Chemical Education, 37(3):5-12.

[2] Pan Jing, Ma Xinchuan. (1999) A review of Rogers' "student-centered" teaching idea[J]. Foreign Educational Research, (3):1-5.

[3] Tian Xin. (2020) The construction of "student-centered" university teaching quality assurance system[J]. Shanghai Educational Evaluation Research, 9(01):13-17.

[4] Lu Wancheng. (2016) Smart education--a new realm of education informatization [J]. Education Forum, (03):7.

[5] Ma Huan. (2020) Exploring the innovation of teaching mode of Civics and Political Science class from flipped classroom to wisdom classroom [J]. School party construction and ideological education, (16): 4850. 